\title{
La nation au singulier et au pluriel. L'avenir de la culture nationale comme " paradigme " de la société québécoise
}

\section{Gérard Bouchard}

Numéro 25, 1995

Être ou ne pas être québécois

URI : https://id.erudit.org/iderudit/1002292ar

DOI : https://doi.org/10.7202/1002292ar

Aller au sommaire du numéro

\section{Éditeur(s)}

Département de sociologie - Université du Québec à Montréal

ISSN

0831-1048 (imprimé)

1923-5771 (numérique)

Découvrir la revue

Citer cet article

Bouchard, G. (1995). La nation au singulier et au pluriel. L'avenir de la culture nationale comme " paradigme » de la société québécoise. Cahiers de recherche sociologique, (25), 79-99. https://doi.org/10.7202/1002292ar
Résumé de l'article

Le texte est une tentative de mise au point sur l'état et l'avenir du nationalisme dans la société québécoise. Il se veut une défense contre les remises en question périodiques dont fait l'objet la légitimité même de l'idée nationale au Québec, dans la mesure où elle est souvent associée à une menace pour les libertés individuelles et, plus particulièrement, pour le sort des communautés ethniques. À cet égard, six modèles d'aménagement collectif sont passés en revue et critiqués, l'un d'entre eux étant privilégié. Par ailleurs, l'avenir du nationalisme est envisagé en référence avec les importantes transitions dans lesquelles la culture québécoise est engagée depuis quelques décennies, notamment le passage d'un paradigme de la survivance à un paradigme d'émergence, ainsi que la remise en question des vieilles allégeances européennes au profit d'une insertion dans l'américanité. Suit un plaidoyer en faveur d'une forme renouvelée de nationalisme, au pluriel et au singulier, à contenu social, et largement affranchi de l'ethnicité. Une dernière partie propose un commentaire critique du nationalisme actuel, de ses postulats, ses paris, ses enjeux; y sont énoncées les conditions devant permettre à l'idée nationale d'encadrer efficacement le développement de la société québécoise dans le respect de toutes ses composantes. 


\section{La nation au singulier et au pluriel. L'avenir de la culture nationale comme «paradigme» de la société québécoise*}

Gérard BOUCHARD

Dans les pages qui suivent, la nation désigne un mode particulier d'intégration et de représentation politique et culturelle d'une collectivité. Ce mode se caractérise par $a$ ) un sentiment d'appartenance exprimé dans des symboles et nourri par une mémoire, $b$ ) des éléments de culture commune (la langue, les valeurs) c) un consensus autour de règles fondamentales prises en charge par le droit, et $d$ ) une volonté partagée de développement collectif soutenue et arbitrée par un État souverain. Par nationalisme, nous entendons l'idéologie qui vise soit à promouvoir l'action d'une collectivité aspirant au statut de nation, soit à défendre les attributs d'une collectivité nationale dont le statut est menacé, soit encore à stimuler les actions ou projets de développement dans une telle communauté en les inscrivant dans la thématique nationale ${ }^{1}$.

Ce texte est motivé par les remises en question périodiques dont fait l'objet la légitimité même de l'idée nationale dans le cadre québécois. Ces remises en question ne nous semblent pas fondées. Le modèle de rechange qui est le plus souvent proposé consiste essentiellement dans un cadre contractuel: des conventions de droit auxquelles les individus adhéreraient rationnellement, rejetant dans la sphère privée ou

\footnotetext{
* Un résumé de ce texte est paru dans le journal Le Devoir des 8 et 9 juin 1994. L'auteur remercie, pour leurs utiles commentaires, Yvan Lamonde, Marc Saint-Hilaire et Ronald Rudin.

1 Cette définition diffère quelque peu de celle qu'a proposée $\mathrm{F}$. Dumont (Genèse de la société québécoise, Montréal, Boréal, 1993, 393 p.) en référence au XIXe siècle québécois. Le nationalisme y est donné comme une idéologie globale («une référence première», p. 276) qui recoupe toutes les dimensions de la vie collective et qui a donc préséance sur toutes les autres, mais n'inclut pas nécessairement la référence à l'État. Sur ce point, nous nous rallions à des auteurs comme B. Anderson, Imagined Communities. Reflections on the Origin and Spread of Nationalism, 2e éd., Londres, Verso, 1991, 224 p.; E. Gellner, Nations et nationalisme, Paris, Payot, 1989, 208 p.; P. Alter, Nationalism, Londres, Edward Arnold, 1985, 172 p.
} 
communautaire les manifestations «subjectives» et symboliques, dans lesquelles se trouve inclus tout ce qui relève de l'identification et de l'appartenance. En simplifiant, le Québec d'aujourd'hui se retrouverait devant l'alternative suivante: soit une forme d'intégration collective sous le couvert de la conscience nationale, soit une société de droit segmentée selon le modèle du multiculturalisme ou, plus simplement encore, déployée dans les individualités qui la composent.

La position défendue ici pourrait s'énoncer comme suit: il ne paraît pas justifié, dans le contexte québécois, de condamner l'idée nationale comme représentation ou comme conscience collective; par contre, il ne sera pas possible au nationalisme québécois de remplir sa fonction de paradigme intégrateur s'il ne poursuit pas l'importante transition dans laquelle il est engagé depuis quelques décennies.

\section{La nation québécoise: des modèles d'aménagement}

L'alternative qui vient d'être énoncée est commode mais réductrice. En réalité, si l'on tient compte des extrêmes et des variantes, l'éventail des choix qui s'offrent aux Québécois en matière de rapports ethniques et culturels est plus étendu. On pourrait dire que six modèles ont été proposés durant les trente dernières années pour aménager l'identité québécoise dans un contexte d'immigration et de diversification. Ce sont: 1) le bilinguisme et le biculturalisme, 2) l'assimilation, 3) l'intégration, 4) l'interculturalisme, 5) l'individualisme juridique, et 6) le multiculturalisme. Il est utile de caractériser brièvement ces formules qui, pour être très familières, n'en souffrent pas moins d'une certaine confusion. Cette présentation n'a cependant pas d'ambition théorique, et encore moins épistémologique; il s'agit seulement de poser des balises au départ, en se référant aux diverses thèses qui ont alimenté récemment le débat public au Québec.

Bilinguisme et biculturalisme

Ce modèle, dans l'acception collective qui lui fut donnée au cours des années soixante, est devenu marginal. La défaveur dans laquelle il est tombé auprès de la très grande majorité des Québécois tient à des raisons sociologiques (la théorie d'une société biculturelle n'a pu être faite et l'histoire n'en offre pas d'exemple) tout autant que politiques (il y avait fort à craindre que la société francophone ne soit appelée à être plus bilingue et biculturelle que la société anglophone). 


\begin{abstract}
Assimilation
Comme la précédente, cette formule ne trouve plus guère de promoteurs sur la place publique. Selon un consensus désormais largement établi, la nation québécoise doit s'accommoder de la diversité et s'incorporer les spécificités culturelles des nouveaux venus plutôt que de chercher à les effacer.
\end{abstract}

\title{
Intégration
}

Ce modèle rallie la plus grande partie de la population, mais il le doit en partie à son imprécision. D'abord, l'exigence d'un minimum d'intégration relève du sens commun. En outre, la notion peut accueillir des contenus assez divers. Pour cette raison peut-être, on lui a fréquemment associé les concepts de convergence, de creuset et, plus récemment, de culture publique commune. Deux remarques à ce sujet. D'un côté, ce serait une erreur de croire qu'il est possible de définir $a$ priori le contenu de cette culture; c'est plutôt la dynamique largement imprévisible - de la société québécoise qui en décidera ellemême, sur trois, quatre ou cinq générations, à travers les aléas de la vie quotidienne comme dans l'addition des choix politiques à l'échelle locale et nationale. Par ailleurs, ces exercices de définition demeurent utiles parce qu'ils sensibilisent les francophones de vieille ascendance aux nouvelles données ethniques et parce qu'ils préparent les néoQuébécois à une insertion qu'ils avaient peut-être conçue autrement. Quoi qu'il en soit, il est parfaitement légitime, de la part de la société d'accueil, d'imposer quelques règles fondamentales, qui sont au cœur de la vie collective et par lesquelles tous les citoyens doivent être liés juridiquement ou moralement. Font partie de ces règles: le respect de valeurs premières telles la démocratie, l'égalité, les libertés civiles, la tolérance; et l'apprentissage de la langue française, comme dénominateur commun de la culture québécoise - sans exclure évidemment la survie des autres langues, mais comme langues secondes, en accord avec la réalité prépondérante de la culture québécoise comme francophonie nord-américaine ${ }^{2}$.

Au-delà de cette zone protégée, le champ culturel doit demeurer ouvert, son avenir étant laissé à la discrétion des acteurs. Il existe néanmoins un puissant moyen d'encourager l'intégration culturelle au sein des non-francophones et des néo-Québécois: c'est la participation au fonctionnement des institutions publiques et des centres de décision et d'influence. De toute évidence, c'est la manière la plus efficace (et la

2 Voir, à ce sujet, G. Bouchard, F. Rocher et G. Rocher, Les francophones québécois, Montréal, Conseil scolaire de l'île de Montréal, 1991, 87 p. 
plus démocratique qui soit) de stimuler parmi les communautés dites ethniques ou culturelles l'intérêt pour la société québécoise et les objectifs qu'elle se donne. Iri, la balle est dans le camp de la société d'accueil qui a le devoir, ne serait-ce que par souci de cohérence, de soutenir des politiques d'accès à des postes dans la fonction publique, dans les médias, dans l'enseignement et le reste. Mais en retour, tout cela suppose, bien sûr, que les personnes auxquelles ces politiques sont destinées soient capables d'œuvrer en français. De toutes les formules proposées, notre préférence va à une intégration de ce genre, fondée sur le respect des droits et des prérogatives, un souci de la diversité et une conception réaliste de la réciprocité.

\section{Interculturalisme}

L'interculturalisme est une autre notion très polyvalente qui doit à son caractère ambigu une partie de son rayonnement. Dans la mesure où il se veut un appel à l'ouverture, au respect de l'autre et au dialogue, ce modèle fait l'unanimité. Mais il s'apparente souvent au multiculturalisme, dont il offre quelques variantes. Sous d'autres formes, il peut aussi devenir une des nombreuses versions du modèle de l'intégration et il appelle alors les mêmes commentaires.

\section{Individualisme juridique}

Dans son acception la plus stricte inspirée du néolibéralisme, ce modèle est le plus irréaliste dans la mesure où il contient implicitement une sorte de négation de la vie collective, des appartenances, des solidarités et des symboles qui s'y greffent. La dynamique sociale y est réduite aux comportements et aux choix des acteurs individuels ${ }^{3}$. Plus fondamentalement, le modèle est inspiré par une critique de l'État sauf lorsque celui-ci se fait le gardien des droits individuels - et par une méfiance envers le social, tenu pour un lieu d'irrationalités et d'oppression. Ces prémisses ne sont évidemment pas dénuées de fondement, surtout lorsqu'on les considère dans leurs références européennes. Elles doivent pourtant être calibrées à la lumière du contexte québécois, très marqué historiquement par les valeurs communautaires (tout comme le Canada lui-même), sans que la démocratie ait eu à en souffrir. On peut même attribuer à ce trait quelques-unes des réalisations dont les Québécois sont le plus fiers (mouvement Desjardins, assurance-maladie et autres grandes initiatives sociales,

3 À l'origine pourtant, l'individualisme libéral se conciliait avec les exigences de la vie communautaire, comme le rappelait récemment James Tully dans une entrevue donnée au journal Le Devoir (16 janvier 1995, p. B1). 
économiques et culturelles issues de la Révolution tranquille). Le modèle individualiste ne résiste pas en outre à l'épreuve de l'analyse sociologique la plus élémentaire: dans toute population, des structures prennent forme, une vie sociale s'institue, des aménagements culturels, symboliques, se mettent en place. En réalité, le modèle en cache un autre qui épouse concrètement la forme du multiculturalisme. Une dernière réticence naît du fait que cette conception néolibérale, qui est censée fonder la nation «civique», n'est pas innocente politiquement dans le contexte canadien où elle sert souvent à discréditer le nationalisme québécois: on oppose alors comme deux contraires une conception canadienne, soucieuse du respect des libertés, à une conception québécoise axée sur les privilèges de la collectivité (c'est-àdire de la majorité), au détriment des individus et des minorités.

\section{Multiculturalisme}

Essentiellement, ce modèle préconise le développement à part entière et sur un pied d'égalité de toutes les composantes ethniques présentes dans une société. Il ne nous paraît pas approprié au contexte québécois, pour les raisons suivantes, dont certaines sont bien connues:

- L'espace culturel québécois n'est pas vide, on ne peut en refaire d'emblée le dessin; il est déjà structuré à partir d'une composante principale qui représente les quatre cinquièmes des habitants. Cette composante s'est mise en place à travers une histoire qui aura bientôt quatre siècles et qui a donné lieu à l'occupation d'un territoire, au déploiement d'une société et d'une culture, à l'élaboration d'une mémoire et d'un projet national: depuis deux siècles en effet, la collectivité francophone s'active à la poursuite d'une certaine idée d'elle-même. Toute tentative pour plier cet espace aux critères du multiculturalisme risque d'installer les communautés culturelles en marge de la nation, laquelle serait alors prise en charge par les seuls francophones. Cette perspective n'est pas souhaitable et, du reste, elle ne correspond aux vœux ni des unes ni des autres ${ }^{4}$.

- Sur les plans sociologique et politique, on peut même se demander si le modèle multiculturel est viable. Notons au passage qu'il ne compte guère de précédents heureux. Comme le nationalisme, il a connu sa part de dérapages (l'exemple yougoslave nous le rappelle) et l'expérience

4 Cette ligne de pensée est soutenue par de nombreux néo-Québécois. Elle est partagée, notamment, par des intervenants aussi peu suspects d'intolérance que C. Corbo (Mon appartenance: essais sur la condition québécoise, Montréal, VLB éditeur, 1992, 119 p.) ou A. Jacobi («Droit de vote dans la légalité», Le Devoir, 17 janvier, 1995, p. A7). 
canadienne, largement dictée par le pragmatisme politique, est encore trop jeune pour servir de témoin ${ }^{5}$. Plus généralement, il faut aussi s'interroger sur les chances d'une société qui ne fonderait son intégration que sur la rationalité individualiste du droit et de la citoyenneté. Séduisante par son universalité et sa rectitude, cette conception n'en est pas moins trompeuse parce qu'elle fait fi, comme nous venons de le signaler, de la symbolique identitaire et de la dynamique des appartenances qui accompagnent toute vie collective. Inévitables, ces deux dimensions sont par ailleurs indispensables: ce sont elles qui, souvent, nourrissent les solidarités, les mobilisations à contenu social ou humanitaire, les politiques de développement, les formules de partages collectifs, les luttes d'émancipation ou de résistance ${ }^{6}$. En certaines occasions, il est vrai, elles s'emballent, se laissent porter par l'ethnicité exacerbée, nourrissent des mouvements d'oppression; l'idée nationale doit alors être réprimée. Mais à cet égard, en quoi le multiculturalisme représente-t-il un remède à long terme puisqu'il propose essentiellement d'aménager la vie collective sur la base même des ethnicités juxtaposées et d'en faire la promotion? Le modèle que nous proposons ne consiste pas à remplacer ces ethnicités par une autre mais à les articuler à une culture nationale commune axée sur la poursuite de valeurs universelles.

- Une autre raison de rejeter ce modèle dans le contexte québécois tient dans la contradiction qu'il contient. Chacun soutient, avec raison, que la diversité dont l'immigration est porteuse est un gage d'enrichissement pour la culture québécoise. Mais cet énoncé n'a de sens que dans l'hypothèse d'une intégration: il faut bien un dénominateur commun qui permette la communication et l'échange, et des institutions qui soutiennent ces interactions. L'enrichissement ne peut naître du cloisonnement.

En résumé, dans l'optique d'une nation québécoise à la fois soucieuse de son avenir et respectueuse de la diversité, c'est le modèle de l'intégration qui paraît le plus réaliste, mais une intégration prudente et souple, modulée en fonction de certains droits acquis (ceux des Anglo-Québécois et des autochtones, par exemple), qui sait tenir compte d'impératifs contextuels et ne pas s'enfoncer dans des querelles de turban, de foulard ou de ceinture fléchée. Et quoi qu'il en soit, il y a

5 On sait qu'elle a commencé à faire l'objet de critiques par ceux-là mêmes qui devraient en être les premiers bénéficiaires (voir en particulier N. Bissoondath, $L e$ marché aux illusions: la méprise du multiculturalisme, Montréal, Boréal-Liber, 1994, 242 p.).

6 À ce sujet, voir les textes présentés dans W. Kaplan (dir.), Belonging: The Meaning and Future of Canadian Citizenship, Montréal et Kingston, McGill et Queen's University Press, 1993, 387 p. 
peu de chance au Québec (sauf à très long terme) d'ériger une conscience collective en dehors du prisme national. Cela dit, quel est l'état du nationalisme québécois et dans quelle mesure est-il compatible avec le modèle préconisé?

\section{De la survivance à l'émergence}

On pourrait dire que, jusqu'au milieu du XXe siècle, le nationalisme québécois a été marqué par le paradigme de la survivance, c'est-à-dire: la conscience d'un péril et d'une fragilité collective, un sentiment d'angoisse et d'humiliation source de ressentiment, des réactions d'impuissance prenant la forme tantôt de stratégies défensives, tantôt d'utopies un peu échevelées (la construction du Nord, le messianisme continental...), un état permanent d'alerte constitutionnelle ponctué de défaites, la conviction de devoir assurer la survie culturelle au détriment du développement économique et social ${ }^{7}$. Il ne s'agit pas vraiment de condamner cet ancien paradigme et toutes les perceptions ou représentations collectives qui lui furent associées. Il suffit de constater qu'il avait ses racines, ses raisons, qu'il a rempli une fonction historique importante en préservant à sa façon l'avenir de la francophonie québécoise, en la constituant comme héritage. Il faut aussitôt ajouter qu'il n'a plus sa place, qu'un autre l'a remplacé: le paradigme de l'émergence. Grâce aux institutions qui ont été mises en place ou consolidées depuis la Révolution tranquille, à cause aussi d'une volonté collective qui ne s'est jamais démentie depuis plus de deux siècles ${ }^{8}$, il semble bien qu'à moyen terme la survie culturelle du Québec soit relativement assurée. Cette collectivité peut se penser désormais autrement que comme une marginalité, ou comme un accident de l'histoire; elle a du reste commencé à se poser comme acteur d'une histoire, très modeste bien sûr, mais acteur tout de même.

Le paradigme de la survivance, dont le dernier grand représentant fut le chanoine Groulx (Notre maître le passé), ne peut pas fournir les définitions et les orientations appropriées aux situations et aux enjeux des temps présents. D'abord parce qu'il ne peut fonder qu'un nationalisme ethnique alors que la société québécoise a besoin d'une vision qui interpelle tous ses membres. Ensuite, parce que l'ancien nationalisme enfermait le Québec dans une relation bilatérale, trop étroite et sans issue, de revendication et de guérilla avec le gouvernement canadien; or

7 F. Dumont (Genèse de la société québécoise, ouvr. cité) a parfaiternent reconstitué la formation et l'évolution de ce paradigme jusqu'à la fin du xıxe siècle; il n'est pas utile d'en dire plus.

8 Notre point de référence ici est le début du régime anglais, depuis la défaite militaire de 1760 . 
le destin des États contemporains se joue sur plusieurs axes, à l'échelle internationale. Une dernière raison tient aux transformations qu'a connues le nationalisme. Celui qui s'implante au Québec depuis quelques décennies n'est plus motivé par le ressentiment, par une volonté de repli ou par quelque nostalgie, non plus que par une exaltation de l'ethnicité; il est commandé par l'ambition de créer une patrie qui apporte sa contribution originale à l'œuvre de civilisation et par l'utilité d'aménager des formes politiques qui correspondent aux nouvelles réalités sociales et culturelles.

La notion d'émergence fait écho à la fois aux évolutions récentes, aux tendances actuelles et à l'élan qui pourrait en résulter, si telle était la volonté des Québécois. Depuis quelques décennies, la société - et en particulier la culture - québécoise est engagée dans une immense transition qui n'a pas encore été vraiment nommée. Cette transition progresse selon plusieurs trames, par exemple: l'ouverture à la diversité, le passage d'un nationalisme ethnique à un nationalisme social $^{9}$, la politisation du sentiment national désormais pris en charge par des partis politiques à l'échelle québécoise et canadienne, la mondialisation des références et des échanges, etc. Mais le glissement le plus important peut-être est celui qui a remis en question l'allégeance traditionnelle du Québec à l'endroit des cultures française et européenne au profit d'une insertion dans l'américanité. L'histoire culturelle du Québec entre le milieu du XIXe siècle et le milieu du XXe présente en effet un intéressant paradoxe. Contrairement à ce qui s'est produit dans la plupart des nouvelles collectivités créées depuis le XVIe siècle au gré de transferts migratoires intercontinentaux en provenance de l'Europe ${ }^{10}$, le Québec a voulu se constituer comme un prolongement et une réplique de la France et il a longtemps projeté son avenir en termes de fidélité à ses racines, de continuité avec la mère patrie. Or, dans son voisinage immédiat et à la même époque, les États-Unis mettaient en forme un projet inverse. Le contact avec le Nouveau Monde y entraînait une volonté de rupture (culturelle et politique) avec le vieux continent et inspirait des rêves de recommencement, de reconstruction collective. Grâce aux immenses ressources des nouveaux espaces, une nouvelle nation allait prendre son essor, nourri par l'innovation, le dynamisme, le progrès. Le contraste est frappant avec le Québec qui, après 1840 (en faisant la part de quelques courants minoritaires), adoptait peu à peu les réflexes d'une vieille collectivité: nostalgie des origines, repli sur les acquis, durcissement face aux changements, angoisse devant l'avenir.

9 Ce qualificatif doit être pris dans son acception la plus large, empruntée à la tradition sociologique. Il renvoie aux principales composantes d'une collectivité.

10 Cela inclut toutes les populations des Amériques, et d'autres pays aussi comme la Nouvelle-Zélande ou l'Australie. 
Il faut toutefois insister sur deux importantes nuances. D'abord, les réticences affichées par la plus grande partie des élites à l'endroit de l'américanité en général (et plus particulièrement à l'endroit du «péril» états-unien) n'ont guère touché les classes populaires ${ }^{11}$. Peu sollicité par les modèles culturels français et européens, qui derneuraient des références largement élitaires, le peuple des villes et des campagnes se laissait plutôt séduire par les États-Unis et les promesses du continent. En plus, dans ses comportements quotidiens, il s'en remettait plus volontiers à ses propres modèles culturels (linguistiques, par exemple), dans une relative insouciance de l'orthodoxie que ses guides tentaient de lui inculquer ${ }^{12}$. Par ailleurs, il semble bien que jusque dans les années 1830, l'évolution de la société québécoise avait suivi un cours assez analogue à celui des États-Unis. Une thèse récente a même démontré que le mouvement patriote était un programme de rupture inspiré par un projet de développement et de république à l'américaine $^{13}$. Le cours de cette évolution a cependant été détourné par l'échec de l'insurrection de 1837-1838 et par la réprimande constitutionnelle qui a suivi. C'est ce revirement qui a progressivement amené la majorité des dirigeants québécois à relancer le paradigme de la survivance culturelle dans la continuité. Mais depuis quelques décennies, le Québec est de nouveau engagé sur cette voie de la rupture et de l'affirmation collective, sollicité par un programme de reconstruction selon un paradigme non plus de survivance mais d'émergence ${ }^{14}$. Or il est intéressant de noter que le nationalisme actuel

11 Entendons ici principalement: l'ensemble des travailleurs manuels.

12 Voir, à ce sujet, G. Bouchard, «Une nation, deux cultures. Continuités et ruptures dans la pensée québécoise traditionnelle (1840-1960)», dans G. Bouchard (dir.), avec la collaboration de S. Courville, La construction d'une culture. Le Québec et l'Amérique française, Québec, Presses de l'Université Laval, 1993, p. 3-47. Y. Lamonde a également exploité ce thème (voir «American cultural influence in Quebec: A one-way mirror», dans A. O. Hero et M. Daneau (dir.), Problems and Opportunities in U.S.Quebec Relations, Boulder et Londres, Westview Press, 1984, p. 106-126; et «L'ambivalence historique du Québec à l'égard de sa continentalité: circonstances, raisons et signification», dans G. Bouchard et Y. Lamonde (dir.), Québécois et Américains: la culture québécoise aux XIXe et XXe siècles, Montréal, Fides, 1995, p. 61-84).

13 L.-G. Harvey, Importing the Revolution. The Image of America in French-Canadian Political Discourse (1805-1837) thèse de doctorat en histoire, University of Ottawa, XI, 1990, 508 p. Sur tout ce qui précède, voir G. Bouchard, art. cité; G. Bouchard, «Le Québec comme collectivité neuve. Le refus de l'américanité dans le discours de la survivance», dans G. Bouchard et Y. Lamonde, ouvr. cité, p. 3-47.

14 On le voit dans presque tous les domaines de la culture, en particulier dans l'évolution de la littérature, de la peinture, de l'architecture, etc. (G. Bouchard, «Une nation, deux cultures..., art. cité; et Y. Lamonde, «L'ambivalence historique du Québec à l'égard de sa continentalité..., art. cité). 
se propose comme le vecteur de cette opération, après avoir été pendant un siècle l'instrument de la continuité.

\section{En faveur d'un nationalisme québécois}

Il importe d'abord de rappeler que les grandes réorientations qui viennent d'être évoquées, loin de récuser le nationalisme, l'ont au contraire ranimé en lui donnant d'autres contenus et en lui assignant d'autres finalités. Il est remarquable également que les grandes réformes réalisées depuis le début de la Révolution tranquille ont soit été motivées plus ou moins directement par cette idéologie, soit contribué à l'alimenter. Une forme de nationalisme a survécu même parmi de nombreux partisans de l'option fédéraliste, chez qui le régime fédéral est perçu comme étant le moyen le plus réaliste d'assurer l'émancipation du Québec. En fait, aucun grand projet de changement (de gauche comme de droite) n'a pu être pensé depuis cinquante ans et plus au Québec sans qu'il ne s'articule d'une manière ou d'une autre à l'idée nationale. De toute évidence, on est en présence d'une donnée sociologique profondément enracinée avec laquelle il faudra composer pour longtemps encore. Il apparaît finalement peu utile à moyen terme de se demander si l'avenir de la société québécoise doit emprunter ou non la voie du nationalisme, comme si un éventail d'options lui était vraiment offert; la question que pose surtout l'actualité est celle de l'avenir de ce nationalisme, et plus précisément des orientations qu'il faut lui imprimer.

Nous croyons que cet avenir du nationalisme québécois doit être pensé à la fois au pluriel et au singulier. Au pluriel, d'abord, par souci et respect de la diversité, à partir du dénominateur commun évoqué plus haut, mais en tenant compte également d'une nécessaire référence historique comme l'un des éléments constitutifs de la conscience collective (nous y reviendrons). Au singulier aussi parce que l'idéologie nationaliste est essentiellement la mise en forme d'un sentiment d'appartenance, d'une solidarité qui est le siège de l'action collective - c'est pourquoi elle suppose l'exercice des pouvoirs normalement dévolus à l'État ${ }^{15}$. En somme, la singularité de la conscience nationale prend racine à la rencontre d'un territoire, d'une collectivité en mouvement, d'une culture commune à promouvoir, d'un État. Comment cette conception de la nation comme entité sociologique et comme acteur collectif singulier peut-elle encore se justifier dans le contexte du XXIe siècle?

15 Mais ce dernier corollaire ne serait pas fondé si la nation se repliait sur l'ethnicité. 
- Il importe de favoriser la diversité culturelle à l'échelle où elle est le plus menacée, en l'occurrence à l'échelle internationale. D'une façon générale, la civilisation ne peut que s'enrichir du fait que soit préservée la mosaïque des cultures nationales. Nous plaidons à la fois pour la nation au pluriel et pour la pluralité des nations.

- N'y a-t-il pas lieu de se méfier un peu des modèles dits transnationaux, mondialistes, cosmopolitistes? Ces modèles se donnent comme une critique de l'idée nationale, au nom des valeurs universelles. À ce titre, ils s'enracinent dans une tradition humaniste extrêmement riche en Occident et ils procèdent de finalités éminemment respectables. Mais le parcours qu'ils proposent pour passer du particulier à l'universel s'adresse surtout à la culture savante et n'est pratiquement accessible qu'à une élite. Essayer d'en étendre la portée à l'ensemble de la collectivité ne conduirait qu'à accentuer l'uniformisation qui est déjà le lot de la culture de masse. À l'échelle mondiale en effet, la diffusion culturelle est structurée par des rapports de forces, elle est commandée par des réseaux d'intérêts dont l'enjeu est la consommation à grande échelle ${ }^{16}$. Dans ces conditions, l'international n'est pas nécessairement synonyme d'universel. Le mondialisme offre somme toute une voie marginale à l'intention d'une minorité privilégiée à laquelle appartiennent tous les intellectuels; du point de vue de la nation, il faut certes en retenir l'idéal mais non les modalités. À cet égard, il paraîtra plus réaliste sans doute de proposer l'universel comme une tendance ou une direction à préconiser à partir et au sein des trames historiques spécifiques dans lesquelles le destin des collectivités nationales s'enracine et s'élabore ${ }^{17}$. L'idéal du pays sans nation et du citoyen sans appartenance fait fi des réalités sociologiques de l'identité, laquelle se projette dans une langue, dans des symboles qui servent de référents, dans une culture qui incarne une vision du monde. Il n'est pas inutile de rappeler aussi que le cosmopolitisme, en culture, sert parfois aussi de caution à la mondialisation de l'économie, c'est-à-dire à l'expansion du capitalisme.

On a tort d'assimiler le nationalisme québécois d'aujourd'hui à un nationalisme ethnique, qui voudrait imposer aux nouveaux venus tous ses traits culturels (incluant la religion, les genres de vie, les traditions coutumières, etc.). Sur ce plan, il est seulement exigé des immigrants qu'ils apprennent la langue de la société d'accueil. Peut-on faire moins? Rappelons qu'au cours des dernières décennies le nationalisme

16 Plus qu'à Madonna ou à McDonald's, il faut penser ici à des phénomènes comme le déclin du cinéma d'auteur en Europe et en Scandinavie, ou la constitution d'empires internationaux dans le monde de l'édition.

17 C'est une conception de ce genre que l'on trouve dans P. Bruckner, Le vertige de Babel, cosmopolitisme ou mondialisme, Paris, Arléa, 1994, 62 p. 
québécois s'est délesté de sa composante religieuse au profit d'un ancrage territorial. Parallèlement, il a aussi opéré un important déplacement vers une culture de convergence (ou: culture publique commune ${ }^{18}$ ) afin d'aménager un lieu collectif plus ouvert à la diversité. Ce n'est pas là le fait d'un nationalisme qui aurait maintenu le cap sur l'ethnicité. Bien au contraire, dans l'esprit de la très grande majorité, l'idée nationale est associée au seul objectif qui la légitime vraiment: produire plus de démocratie, plus d'égalité, plus de civilisation, selon des voies qui sont toujours à réinventer en accord avec les caractéristiques et les traditions propres à chaque collectivité.

- Sur le plan historique, les nations sont des acteurs collectifs et politiques légitimes lorsqu'elles sont sanctionnées par la démocratie et ne sont pas animées par des visées belliqueuses. Le Québec satisfait sans peine à ces deux conditions.

- Les collectivités nationales sont en outre productrices de valeurs, de formes culturelles issues d'expériences inscrites non seulement dans des mémoires, mais aussi dans des sensibilités, des mentalités qui sont des gages de diversité. On peut y voir un élément de stabilisation et de contrepoids dans un contexte de centralisation économique et d'uniformisation culturelle stratégique.

- Il paraît contradictoire de contester la légitimité d'une culture nationale québécoise au nom d'une ouverture à la pluri-ethnicité, en vertu de laquelle on devrait privilégier la pluralité culturelle internationale: c'est alors plaider au moins implicitement pour la survie des autres cultures nationales, considérées, elles, comme un patrimoine de l'humanité. Mais défendre le principe de la mosaïque à l'échelle mondiale, n'est-ce pas aussi légitimer indirectement chacune des entités qui la composent? À nos yeux, c'est cette position qui va dans le bon sens et elle compte parmi ses adhérents de célèbres défenseurs de la diversité des cultures, tels Clifford Geertz et Claude Lévi-Strauss (et la plupart des ethnologues).

- Il reste bien sûr toute cette zone de confusion, de tension, sinon de contradiction, entre la raison et l'identité, entre l'universel et le particulier, entre l'individuel et le collectif. La nation en Occident est née avec la modernité et elle incarne une figure originale de ces antinomies, mais elle ne les a pas créées; elles sont apparues d'une façon ou d'une autre dans toutes les sociétés qui ont accédé à l'écriture,

18 Voir, par exemple, G. Caldwell et J. Harvey, «Le prérequis à l'intégration des immigrants: une culture publique commune au Québec», L'Action nationale, vol. 84 , no 6 , juin 1994 , p. $786-794$. 
au droit et à la pensée savante. On ne peut pas faire sur cette base le procès du nationalisme québécois.

- Finalement: mauvais le nationalisme? dangereux? intolérant? réfractaire aux droits et libertés? Il y a les Serbes, bien sûr, et il y eut les Allemands, et avant eux les Turcs. Mais il y a aussi les Norvégiens et les Hollandais, les Polonais et les Israéliens, les Américains et les Canadiens; pourquoi pas les Québécois? Il presse de chasser la confusion entretenue sur ce sujet par quelques polémistes. Le nouveau nationalisme québécois se donne comme un appel, un élan en faveur d'idéaux collectifs poursuivis dans le cadre d'une communauté politique. Il veut se situer dans la tradition politique et philosophique qui a servi de rampe de lancement à la modernité, au libéralisme, à la démocratie, et plus tard aux mouvements de décolonisation. Par contre, l'ethnicisme est une volonté de puissance et de domination qui s'exerce aux dépens des individus et des autres collectivités; il consiste à exalter et à imposer des traits, des particularités culturelles tenues pour supérieures. Il est vrai qu'aucun nationalisme n'est tout à fait à l'abri de cette déviation, tout comme aucune religion n'est immunisée contre les inquisitions ou autres formes d'intégrisme. A-t-on pensé, pour autant, interdire les religions?

\section{Des postulats, des enjeux, des paris}

Les définitions et opinions énoncées jusqu'ici reposent sur quelques postulats et conditions sur lesquels il nous faut maintenant jeter un regard critique.

\subsection{Les illusions de la singularité}

Jusqu'à une période assez récente, autant les historiens que les sociologues et politologues québécois ont souvent cultivé une approche exclusive - pour ne pas dire ethnocentrique - dans leur interprétation du passé et du présent. Il est frappant que les références appuyant et nourrissant les analyses étaient puisées quasi exclusivement dans la réalité québécoise, comme si ce destin était unique, ou comme si on craignait de banaliser le drame national en ouvrant la société québécoise à la comparaison ${ }^{19}$. Encore ici, la problématique de la survivance a imposé son paradigme, l'ancien nationalisme traçant aux sciences

19 Il y a des exceptions, bien sûr, et même de très heureuses - par exemple, le recueil préparé par R. Breton, G. Houle, G. Caldwell, E. Mokrzycki et E. Wnuk-Lipinski (dir.), National Survival in Dependent Societies. Social Change in Canada and Poland, Ottawa, Carleton University Press, 1990, 389 p. 
sociales leurs aires de recherche et leurs lignes d'interprétation ${ }^{20}$. Le dossier de la Révolution tranquille pourrait ici servir d'exemple: il est surprenant qu'on n'ait pas davantage songé à rapprocher cette conjoncture de changement précipité avec ce qui s'est passé à peu près à la même époque dans d'autres provinces canadiennes (par exemple au Nouveau-Brunswick) et d'autres pays scandinaves ou européens, en particulier les pays de l'Est entre 1950 et $1990^{21}$. Dans cet esprit, il est utile d'imaginer des interrogations et des orientations de recherche qui auraient dû naturellement être inscrites à l'ordre du jour et que la pensée québécoise a ignorées. Nous avons déjà évoqué, à ce propos, le refus persistant de se percevoir et de se projeter comme population neuve, sauf au premier tiers du XIXe siècle.

Le paradigme de la survivance a inspiré à l'historiographie et aux sciences sociales des axiomes dont elles ont mis beaucoup de temps à se défaire. L'un d'entre eux consacrait le caractère essentiellement distinct de la société québécoise au sein des autres populations d'Amérique. Cette insistance sur la spécificité a conduit les scientifiques à traiter comme singuliers des phénomènes qui ne l'étaient pas et à leur trouver des explications non moins singulières; en voici quelques exemples reliés à la société rurale: la force de la famille découlait des valeurs catholiques, la fécondité élevée était motivée par la conscience nationale (la fameuse «revanche des berceaux»), la colonisation était une ouvre patriotique, la vigueur du sentiment religieux était héritée des vieilles traditions françaises, et le reste. En réalité, sous tous ces rapports, la société québécoise reproduisait sensiblement les traits des sociétés canadienne-anglaise et états-unienne à la même époque ${ }^{22}$. Ces exemples illustrent la nécessité d'une réflexion comparative et d'une critique des représentations collectives inspirées par la conscience nationale, hier comme aujourd'hui.

20 J.-J. Simard, «Le chemin de croix: nation et sciences sociales au Québec», dans G.-H. Lévesque et autres (dir.), Continuités et rupture: Les sciences sociales au Québec, 2 t., Montréal, Presses de l'Université de Montréal, 1984, p. 507-529; M. Fournier et L. Maheu, «Nationalismes et nationalisation du champ scientifique québécois», Sociologie et sociétés, vol. 7, no 2, novembre 1975, p. 89-114; G. Bouchard, «Une nation, deux cultures..., art. cité.

21 En ce qui concerne les pays de l'Ouest, il est aisé de pointer d'importants éléments d'une conjoncture commune: prospérité économique, réformisme social et politique, intervention de l'État, baby-boom, laïcisation...

22 Nous avons tenté d'en faire la démonstration ailleurs (G. Bouchard, «Le Québec comme collectivité neuve..., art. cité). 


\subsection{Des perspectives comparatives}

Ces prémisses ont conduit à la mise sur pied, au sein de l'Institut interuniversitaire de recherches sur les populations (IREP ${ }^{23}$ ), d'un projet de recherche visant à explorer des perspectives comparées sur les collectivités nationales. On espère ainsi contribuer à élaborer un regard différent, renouvelé, sur le Québec passé et actuel, sous l'éclairage d'autres expériences historiques comparables. Un premier volet porte sur les mythes fondateurs nationaux. Il s'agit d'interroger les représentations collectives - exprimées dans l'historiographie, les idéologies politiques, la littérature, etc. - en tant qu'elles véhiculent une définition des fondements de la communauté nationale, de sa légitimité, de son rôle historique, de son avenir, de ses rapports avec le monde international et de son insertion dans celui-ci. Ces thèmes ont été passablement étudiés déjà dans le cadre du Québec. L'originalité de notre démarche devrait précisément résider dans l'approche comparative et la possibilité qu'elle offre de mettre en perspective le discours québécois et de le soumettre ainsi à un examen largement inédit. L'exercice pourrait conduire à identifier des similitudes et des différences là où on ne s'y attendait pas, à relativiser ou même invalider un certain nombre d'énoncés, à déceler des omissions, des perceptions erronées, voire des contradictions, à mettre en lumière des appréhensions non fondées, des inférences arbitraires, mais aussi à conforter des aperçus, des interprétations, et enfin, à ouvrir des perspectives nouvelles.

Un deuxième volet porte sur l'identité et la citoyenneté; il fait pendant au premier, dont il est une sorte de révélateur. Il s'agit cette fois de s'interroger sur les conceptions dominantes de la citoyenneté, telles qu'elles ont été exprimées dans divers contextes, mais aussi sur la façon dont les prémisses «nationales» ont été traduites formellement dans des définitions de la citoyenneté, des critères d'appartenance à la nation, des conditions et modalités d'intégration (immigration). Encore là, la diversité révélée par la comparaison devrait permettre de mieux situer et éclairer le cas québécois. En outre, l'analyse des règles formelles d'admission dans la nation promet une lecture encore plus explicite des définitions et des visées sous-jacentes ${ }^{24}$.

23 L'IREP s'appuie sur une entente de coopération entre l'Université du Québec à Chicoutimi, l'Université Laval, l'Université McGill, l'Université de Montréal, l'Université Concordia, l'Université de Sherbrooke. Il a remplacé en 1994 l'ancien centre SOREP (Société de recherches sur les populations).

24 Les travaux réalisés dans le cadre du projet sont consignés dans les rapports annuels de l'IREP. L'auteur de ce texte assure la direction du projet, en collaboration avec Yvan Lamonde (Université McGill). Une dizaine de collègues historiens, sociologues, politologues et littéraires y contribuent. 


\subsection{Un regard critique}

Les remarques qui précèdent - en particulier sur les pièges et les séductions de la singularité - suffisent à montrer la pertinence d'un regard critique sur les définitions et représentations véhiculées par le nouveau nationalisme. Ce dernier, par exemple, fait appel à une sorte de décollage collectif assimilable à une deuxième Révolution tranquille et qui mobiliserait les ressources de la collectivité. Sur le plan empirique toutefois, certaines données soulèvent une inquiétude quant aux chances d'une telle mobilisation. C'est le cas de la statistique du décrochage scolaire et de la «diplomation» au secondaire et au collégial, ou de l'analphabétisme dit fonctionnel, cela en dépit des investissements massifs consentis. Sur un autre plan, les nombreux signes d'ouverture et d'apprentissage de la diversité ne font pas oublier d'importants éléments d'immobilisme; par exemple, une statistique de la maîtrise de la langue anglaise (parmi les francophones de naissance) qui augmente peu $^{25}$ ou un enseignement confessionnel qui maintient son emprise sur la population de l'île de Montréal et fait obstacle à la promotion d'une culture commune.

Un autre motif d'inquiétude est relié à l'état de la langue qui, en voulant très légitimement $s$ 'affranchir des canons de la mère patrie au nom de l'authenticité, risque de se marginaliser et d'isoler la culture dont elle est porteuse - alors même que l'effet contraire est recherché par le néonationalisme. Une seconde forme de marginalisation est à craindre, cette fois de l'intérieur. La deuxième moitié du XXe siècle a vu un rapprochement entre la culture des élites et celle des couches populaires, jadis séparées par des allégeances discordantes, européennes dans un cas, américaines dans l'autre. Mais ce rapprochement a un prix: il a eu pour effet de libérer le flot de plus en plus agressif de la culture de masse d'inspiration états-unienne. D'abord réconciliée avec l'américanité, la culture savante pourrait de nouveau se laisser tenter par ses vieilles racines et s'installer dans une marginalité qui trouverait aisément refuge dans des institutions comme l'université ou les médias.

Signalons deux autres points d'interrogation. N'y a-t-il pas un peu de désinvolture dans l'enthousiasme et l'optimisme avec lesquels les Québécois ont accueilli en premier lieu l'Accord de libre-échange avec les États-Unis, et ensuite l'ALENA? Cette attitude reposait pourtant sur un double pari: $a$ ) que l'entrepreneurship québécois saurait soutenir la concurrence nord-américaine plutôt que de livrer progressivement le terrain aux «majors» que sont les Wal-Mart et consorts; $b$ ) que la culture québécoise trouverait à s'émanciper dans un espace économique et

25 De 25 à $30 \%$ en 1971 à $31,3 \%$ en 1991, selon les Recensements du Canada (proportion de francophones se déclarant «bilingues» au Québec). 
médiatique continental devenu de plus en plus ouvert. L'autre question concerne l'intégration des immigrants. $\mathrm{N}$ 'y a-t-il pas là une anomalie du fait qu'une sorte de tabou empêche présentement tout débat de fond sur le volume de l'immigration à admettre - alors même que le Québec est l'un des plus importants receveurs d'immigrants en Occident compte tenu de sa population totale ${ }^{26}$, que les capacités de francisation sont manifestement limitées et que le Québec «ethnique» est en voie de se couper en deux ${ }^{27}$ ?

\section{Conclusion}

Pour s'affirmer pleinement dans les directions évoquées ici, le nouveau nationalisme doit effacer les traces de l'ancien. C'est un travail qui est déjà très avancé, mais on ne doit pas s'attendre à ce qu'il débouche sur une rupture totale avec ce qui a précédé. Le Québec a un passé dont la mémoire doit survivre comme l'une des composantes importantes de l'identité. Toutes les ouvertures à mettre en œuvre à l'intention des nouveaux venus afin de favoriser leur intégration ne peuvent pas faire fi de l'histoire: les Québécois francophones forment une collectivité dont le destin, en deux occasions, a été détourné par les armes; la mémoire qui s'est constituée à même ces traurnatismes et qui se nourrit de très vieilles aspirations collectives a, elle aussi, sa légitimité. S'ajoute à cette mémoire toute la charge symbolique issue d'une longue appropriation de l'espace, des expériences de travail, des interactions sociales, des conflits, des épreuves communes. Certains néoQuébécois suscitent un malaise parmi la population d'accueil lorsqu'ils affichent à l'égard de ce patrimoine affectif et symbolique une sorte de refus et ne semblent montrer de l'intérêt pour la culture québécoise qu'à la condition de n'en parler qu'au futur, comme s'il fallait la réinventer de toutes pièces ${ }^{28}$. Cela dit, il s'agit seulement ici de rendre à

26 Depuis la décennie 1940, le Québec se place au dixième rang des pays industrialisés de plus d'un million d'habitants, ce qui le «classe parmi les premiers territoires d'accueil au monde». Selon M. Paillé, «Aménagement linguistique, immigration et population», texte d'une communication présentée au colloque «Le Québec en changement» tenu le 5 novembre 1993 sous les auspices du ministère des Communautés culturelles et de l'Immigration, à paraître dans les actes du colloque.

27 Cet énoncé n'implique pas de prise de position sur le sujet; il vise simplement à souligner un élément d'incohérence. Une collectivité sûre d'elle-même devrait savoir aborder cette question ouvertement pour la trancher rationnellement. Entre temps, et en dépit de ce que les chiffres annoncent, les Québécois (francophones) sont continuellement confrontés à un incessant procès de xénophobie.

28 Pour une illustration de cet état d'esprit, voir, par exemple, R. Robin, «Défaire les identités fétiches», dans Jocelyn Létourneau (dir.), avec la collaboration de Roger Bernard, La question identitaire au Canada francophone. Récits, parcours, enjeux, horslieux, Québec, Presses de l'Université Laval, coll. «Culture française d'Amérique», 
la conscience historique la place qui lui revient, non pas comme le creuset de la conscience nationale, mais comme l'un de ses éléments constitutifs. Quant à l'objection selon laquelle cette mémoire serait figée dans une culture de la «souche» et ne correspondrait plus aux réalités présentes, elle nous semble ignorer complètement les mutations fondamentales survenues sur ce plan depuis trente ans, notamment dans l'historiographie et la muséographie, mais aussi dans l'ensemble des idéologies et des définitions de la nation. Le discours national québécois est tourné vers l'avenir, et non vers le passé; il fait place à d'importantes préoccupations économiques et sociales ${ }^{29}$ et il a procédé depuis cinquante ans à des réaménagements essentiels sur ce plan.

On peut s'étonner de la vigueur et même de l'agressivité de certaines critiques adressées au néonationalisme québécois. Pourquoi lui fait-on périodiquement des procès d'intolérance, d'autoritarisme, de xénophobie, d'antidémocratisme, de racisme, et même de tribalisme? En quoi ce nationalisme est-il donc si différent de tant d'autres, apparemment irréprochables, et pourquoi faudrait-il tant le craindre? Qu'on le juge plutôt à ses fruits. Il a eu une première chance de s'exprimer dans les années soixante; il a donné la Révolution tranquille, dont les principales réformes avaient un contenu strictement social (santé, éducation) ou plus généralement collectif (nationalisation de l'électricité, Caisse de dépôt et de placement, etc.). Il a eu une deuxième chance de se manifester avec le Parti québécois en 1976; il a alors donné l'assurance-automobile, l'aide juridique, la réforme du financement électoral, la Charte des droits et libertés et la Charte de la langue française (la loi 101) qui officialisait la préséance du français à l'école et au travail, restreignait la liberté de choix des néo-Québécois aux niveaux primaire et secondaire, interdisait l'anglais dans l'affichage public et commercial. Cette dernière législation, motivée par le besoin de protéger la langue française dans un contexte de grande fragilité, a soulevé de nombreuses protestations au nom des libertés individuelles - et elle a aussi servi de prétexte à bien des attaques extravagantes. Avec un recul de vingt ans, on comprend mieux la réaction des AngloQuébécois. Il était peut-être excessif de bannir complètement la langue anglaise dans l'affichage commercial; excessif sur le plan des droits et politiquement imprudent en plus: cette mesure a terni le nationalisme québécois et a fermé la voie à la recherche de compromis avec les anglophones sur des questions essentielles. Les mesures de détente introduites récemment dans cette partie de la loi 101 semblent correspondre à une plus juste vision des choses, à tous égards.

1994, p. 215-240. Aussi, F. Caccia, Golden Eighties, Montréal, Éditions Balzac, 1994, $156 \mathrm{p}$.

29 Les récentes commissions régionales, créées par le gouvernement du Québec, en ont abondamment témoigné. 
Pour le reste, que l'on considère les programmes actuels et les actions tant du Parti québécois que du Bloc québécois, que l'on scrute la feuille de route des acteurs de l'arène politique, qu'on se reporte aux orientations du mouvement syndical, aux opinions de la presse, aux débats des milieux intellectuels, aux tendances, aux symboles exprimés par le théâtre, le cinéma, la littérature: où voit-on le fondement de la mauvaise réputation qu'on voudrait faire aux nationalistes québécois sur le terrain des droits et de la démocratie - si l'on excepte quelques éléments isolés que néanmoins une presse (anglophone, en particulier) se plaît régulièrement à prendre à témoin de l'ensemble de la culture politique québécoise ${ }^{30}$ ?

Finalement, de quelque côté qu'on le regarde, le nationalisme québécois d'aujourd'hui paraît bien inoffensif. On peut même être convaincu que, si on lui donne à nouveau l'occasion de s'affirmer, la société québécoise connaîtra une autre période de dynamisme et de développement. Il subsiste chez les Québécois francophones un rêve américain (au sens continental) qui ne s'est jamais réalisé, un capital de motivation et d'initiative qui n'a pas été pleinement exploité. Allons plus loin: ce nationalisme, dont il y a peu à craindre et beaucoup à attendre, est devenu en réalité nécessaire. Le pire qui pourrait arriver aux Québécois dans les décennies qui viennent serait un décrochage européen et une immersion dans l'américanité qui ne s'accompagneraient pas d'une forte idéologie d'innovation et de construction collective soutenue par la conscience nationale. Autrement, l'avenir américain du Québec se résorbera à la longue dans une culture étatsunienne où le rêve aura été remplacé par la nostalgie.

\section{Gérard BOUCHARD \\ Directeur \\ Institut interuniversitaire de recherches sur les populations (IREP)}

\footnotetext{
30 Ainsi, le chanoine Groulx y est souvent donné comme une référence centrale du nouveau nationalisme, alors même que ce dernier lui tourne le dos. Pour la plupart des moins de cinquante ans, cette figure ne signifie plus rien; pour les autres, elle est devenue marginale. Mais il est vrai que sur le plan institutionnel, sa mémoire officielle survit par une sorte d'inertie, ce qui donne des munitions inespérées à certains critiques du Québec actuel. À ce propos, il est difficile de comprendre la réaction de plusieurs intellectuels francophones à la thèse d'E. Delisle (Le traître et le juif: Lionel Groulx. Le Devoir, et le délire du nationalisme d'extrême droite dans la province de Québec, 19291939, Montréal, l'Étincelle, 1992, 284 p.). Au lieu de se porter à la défense du chanoine, il aurait été plus avisé de reconnaître les faits (dont la grande majorité était déjà connue), de déplorer ce passé (dans lequel de nombreux pays ont trempé, y compris le Canada) et de revenir au présent.
} 
Résumé

Le texte est une tentative de mise au point sur l'état et l'avenir du nationalisme dans la société québécoise. Il se veut une défense contre les remises en question périodiques dont fait l'objet la légitimité même de l'idée nationale au Québec, dans la mesure où elle est souvent associée à une menace pour les libertés individuelles et, plus particulièrement, pour le sort des communautés ethniques. À cet égard, six modèles d'aménagement collectif sont passés en revue et critiqués, l'un d'entre eux étant privilégié. Par ailleurs, l'avenir du nationalisme est envisagé en référence avec les importantes transitions dans lesquelles la culture québécoise est engagée depuis quelques décennies, notamment le passage d'un paradigme de la survivance à un paradigme d'émergence, ainsi que la remise en question des vieilles allégeances européennes au profit d'une insertion dans l'américanité. Suit un plaidoyer en faveur d'une forme renouvelée de nationalisme, au pluriel et au singulier, à contenu social, et largement affranchi de l'ethnicité. Une dernière partie propose un commentaire critique du nationalisme actuel, de ses postulats, ses paris, ses enjeux; y sont énoncées les conditions devant permettre à l'idée nationale d'encadrer efficacement le développement de la société québécoise dans le respect de toutes ses composantes.

Mots-clés: culture nationale, francophonie québécoise, nationalisme, ethnicisme, multiculturalisme, intégration, néo-Québécois, rapports ethniques, survivance, émergence.

\section{Summary}

This article attempts to clarify the status of the state and future of nationalism in Quebecois society. It is a defense against those periodical reconsiderations of the legitimacy of the idea of a Quebecois nation, to the extent that it is often viewed as a threat to individual freedoms and, more particularly, the lot of ethnic communities. In this regard, six models of collective arrangements, one of which is favoured, are reviewed and critiqued. In addition, the future of nationalism is viewed in light of the important transitions under way in Quebecois culture over the past few decades, particularly the shift from a paradigm of survival to one of emergence, as well as the reconsideration of old European allegiances in favour of an insertion into Americanicity. This is followed by a plea for a renewed form of nationalism, plural and singular, having social content, and free of ethnicity. A final section provides a critical commentary on present nationalism, its postulates, its wagers, its stakes; it lays out the conditions that should allow the idea of 
the nation to be an effective framework for the development of a Quebecois society respectful of all its components.

Key-words: national culture, Quebecois Francophone community, nationalism, ethnicism, multiculturalism, integration, neoQuebecois, ethnic relations, survival, emergence.

\section{Resumen}

El texto constituye una tentativa de síntesis sobre el estado actual y el futuro del nacionalismo en la sociedad quebequense. El mismo presenta una defensa contra los cuestionamientos periódicos de la legitimidad misma de la idea nacional en el Quebec, en la medida en que ésta se asocia a una amenaza a las libertades individuales y, más particularmente, a la suerte de las comunidades étnicas. En este sentido, seis modelos de organización colectiva son examinados y criticados, uno de ellos siendo privilegiado por el autor. Por otra parte, el futuro del nacionalismo es percibido en relación a las importantes transiciones en las que la cultura quebequense se ha aventurado desde hace algunas décadas, en especial el pasaje de un paradigma de supervivencia a un paradigma de emergencia, así como el cuestionamiento de antiguas lealtades europeas privilegiando una inserción en la americanidad. El artículo continúa con un alegato en favor de una forma renovada de nacionalismo, en plural y singular, de contenido social y ampliamente liberado de toda etnicidad. Por último, se propone un comentario crítico sobre el nacionalismo actual, sus postulados, sus apuestas y desafíos; y también se enuncian las condiciones que deberían permitir encuadrar eficazmente la idea nacional en el desarrollo de la sociedad quebequense respetando todos sus componentes.

Palabras claves: cultura nacional, francofonía quebequense, nacionalismo, etnicismo, multiculturalismo, integración, neoquebequense, relaciones étnicas, supervivencia, emergencia. 